\title{
Increased risk of left sided colon cancer in patients with diverticular disease
}

\author{
T Stefánsson, A Ekbom, P Sparèn, L Påhlman
}

\begin{abstract}
Certain similar epidemiological characteristics suggest a common aetiology for colon cancer and diverticulosis of the colon. The hypothesis that patients with diverticulosis are at increased risk of developing colon cancer was tested in a retrospective, population based, cohort study in Sweden. A total of 7159 patients (2478 men and 4681 women) who had been given a hospital discharge diagnosis of diverticulosis or diverticulitis of the colon between 1965 and 1983 were followed up during 1985 by means of record linkage procedures. After excluding the first 2 years of follow up, there was not a significant increase in risk (SIR) overall for colon cancer $(\mathrm{SIR}=1 \cdot 2 ; 95 \%$ confidence intervals (CI) $0.9,1.6$ ) or for rectal cancer $(\mathrm{SIR}=1.1 ; 95 \%$ CI $0.7,1.7)$. The observed number of right sided colon cancers was as expected (SIR $=0.9 ; 95 \%$ CI $0.5,1.5)$. In contrast, an increased risk of left sided colon cancer was found both overall (SIR $=1.8 ; 95 \%$ CI $1 \cdot 1,2 \cdot 7)$ and consistently in men and women as well as in different age groups. This risk increased the longer the follow up ( $p$ value for trend $<0.001)$. These results do not support the hypothesis of a common aetiology in diverticular disease and colonic cancer but suggest a causal relationship between diverticular disease and cancer of the left colon.
\end{abstract}

(Gut 1993; 34: 499-502)

Several authors have suggested that diverticulosis and cancer of the colon have aetiologic factors in common, ${ }^{1-5}$ and in the western world the incidence of both has increased this century. ${ }^{1356}$ In contrast, diverticulosis of the colon is rare in populations with a low incidence of colorectal cancer, mostly in developing countries. Migration studies from Israel ${ }^{7}$ and from Hawaii ${ }^{8}$ support the hypothesis that environmental risk factors are important in the aetiology of diverticulosis. Similar results have been reported with regard to colonic cancer among migrants from low to high risk areas. ${ }^{910} \mathrm{~A}$ low fibre diet has been proposed as a risk factor for both diseases. ${ }^{1-311-15}$ The suggestion of a common aetiology has, however, limited empirical support from analytical epidemiological studies. Two smaller studies ${ }^{16}{ }^{17}$ failed to show any association between colon cancer and diverticulosis of the colon. Our report is the first population based cohort study carried out to assess the possible association. All hospital inpatients in the Uppsala health care region diagnosed as having diverticulosis or diverticulitis of the colon between 1965 and 1983 were followed up through 1985 for the occurrence of colorectal cancer.
Subjects and methods

COHORT

The Uppsala health care region, covering six counties, is located in central Sweden and had, during the study period, a population of $1 \cdot 2-1 \cdot 3$ million people. Since there is almost no private inpatient treatment in Sweden, hospital provided medical services are, in effect, population based and referable to the county in which the patient lives. From 1965 until 1983, the Swedish National Board of Health and Welfare received annual reports from all inpatient medical institutions in Sweden and recorded data on individual hospital admissions and discharges in the inpatient register for all inhabitants within the Uppsala health care region. Besides a national registration number, a unique personal identifier assigned to all Swedish citizens, each record contains data on place of residence, hospital department, surgical procedures, and up to eight discharge diagnoses. These diagnoses were coded according to the seventh revision of the International Classification of Diseases until 1968 and according to the eighth revision thereafter. A recent publication estimated that the overall extent of under-reporting to the inpatient register was less than $2 \%$. Severe under-reporting occurred in certain counties during a limited period, representing a few $\%$ only of the estimated total number of hospital admissions. ${ }^{18}$

All patients with records in the inpatient register containing a diagnostic code for diverticulosis (ICD 7 code $572 \cdot 12$ and ICD 8 code $562 \cdot 10$ ) or diverticulitis (ICD 7 code $572 \cdot 11$ and ICD 8 code $562 \cdot 11$ ) of the colon were considered for inclusion in the study. The national registration number allowed us to select the first recorded discharge with this diagnosis for each individual. A total of 7630 individuals had been given a discharge diagnosis of diverticulosis or diverticulitis at least once between 1965 and 1983 and were potentially eligible. We excluded 128 of these because they had been entered in the inpatient register with an incomplete or inconsistent national registration number and were not available for follow up. Through the National Census Bureau and the emigration register we were able to confirm that the remaining members of the cohort were alive and living in Sweden on December 31, 1985. A total of 343 cases were not found in any of these registers, probably because they had been entered in the inpatient register with an erroneous national registration number and they were excluded. The number of patients available to follow up was thus 7159-2478 men and 4681 women. At first discharge, 1410 patients were under the age of 60 years, 1665 were 60 to 69 years, and 4084 were 70 years or older. 
TABLE I Observed number of cases (OBS) and risk of developing colorectal cancer expressed as the standard incidence ratio (SIR), with $95 \%$ confidence intervals in parentheses, according to the localisation of the cancer and gender. The first 2 years of follow up were excluded

\begin{tabular}{|c|c|c|c|c|c|c|}
\hline \multirow[b]{2}{*}{ Site } & \multicolumn{2}{|l|}{ All } & \multicolumn{2}{|l|}{ Men } & \multicolumn{2}{|c|}{ Women } \\
\hline & $O B S$ & SIR & $O B S$ & $S I R$ & $O B S$ & $S I R$ \\
\hline $\begin{array}{l}\text { All colon } \\
\text { Right }+ \text { transverse colon } \\
\text { Descending }+ \text { sigmoid colon } \\
\text { Rectum }\end{array}$ & $\begin{array}{l}43 \\
16 \\
21 \\
22\end{array}$ & $\begin{array}{l}1 \cdot 2(0 \cdot 9-1 \cdot 6) \\
0 \cdot 9(0 \cdot 5-1 \cdot 4) \\
1 \cdot 8(1 \cdot 1-2 \cdot 7) \\
1 \cdot 1(0 \cdot 7-1 \cdot 7)\end{array}$ & $\begin{array}{r}17 \\
6 \\
9 \\
9\end{array}$ & $\begin{array}{l}1 \cdot 6(0 \cdot 9-2 \cdot 5) \\
1 \cdot 1(0 \cdot 4-2 \cdot 5) \\
2 \cdot 2(1 \cdot 0-4 \cdot 2) \\
1 \cdot 2(0 \cdot 6-2 \cdot 3)\end{array}$ & $\begin{array}{l}26 \\
10 \\
12 \\
13\end{array}$ & $\begin{array}{l}1 \cdot 1(0 \cdot 7-1 \cdot 6) \\
0 \cdot 8(0 \cdot 4-1 \cdot 5) \\
1 \cdot 6(0 \cdot 8-2 \cdot 7) \\
1 \cdot 1(0 \cdot 6-1 \cdot 8)\end{array}$ \\
\hline
\end{tabular}

${ }^{\star}$ Including multiple and unspecified sites.

TABLE II Observed number of cases (OBS) and risk of developing colorectal cancer expressed as the standard incidence ratio (SIR), according to the localisation of the cancer and age at first discharge. The first 2 years of follow up were excluded. $95 \%$ confidence limits in parenthesis

\begin{tabular}{|c|c|c|c|c|c|c|}
\hline \multirow[b]{3}{*}{ Site } & \multicolumn{6}{|c|}{ Age at diagnosis of diverticular disease } \\
\hline & \multicolumn{2}{|c|}{$<60 y$} & \multicolumn{2}{|c|}{$60-69 y$} & \multicolumn{2}{|c|}{$>=70 y$} \\
\hline & OBS & $S I R$ & $O B S$ & $S I R$ & $O B S$ & $S I R$ \\
\hline $\begin{array}{l}\text { All colon } \\
\text { Right }+ \text { transverse colon } \\
\text { Descending + sigmoid colon } \\
\text { Rectum }\end{array}$ & $\begin{array}{l}3 \\
0 \\
3 \\
3\end{array}$ & $\begin{array}{l}0 \cdot 8(0 \cdot 2-2 \cdot 3) \\
0 \cdot 0(0 \cdot 4-5 \cdot 7) \\
2 \cdot 0(0 \cdot 3-3 \cdot 6)\end{array}$ & $\begin{array}{r}10 \\
3 \\
6 \\
4\end{array}$ & $\begin{array}{l}1 \cdot 0(0 \cdot 5-1 \cdot 8) \\
0 \cdot 6(0 \cdot 1-1 \cdot 8) \\
1 \cdot 6(0 \cdot 6-3 \cdot 6) \\
0 \cdot 7(0 \cdot 2-1 \cdot 8)\end{array}$ & $\begin{array}{r}30 \\
13 \\
12 \\
8\end{array}$ & $\begin{array}{l}1 \cdot 3(0 \cdot 9-1 \cdot 9) \\
1 \cdot 1(0 \cdot 6-1 \cdot 9) \\
1 \cdot 7(0 \cdot 9-3 \cdot 0) \\
1 \cdot 3(0 \cdot 7-2 \cdot 2)\end{array}$ \\
\hline
\end{tabular}

^Including multiple and unspecified sites.

\section{FOLLOW UP}

Record linkage (based on the national registration number) to the nationwide register of causes of death lead to information on the date of death among those who had died during 1985. The National Swedish Cancer Registry, founded in $1958,{ }^{19}{ }^{20}$ was used to ascertain all incident cancers diagnosed in the cohort from start of follow up until the end of 1985 . The time of observation was calculated from the date of the first discharge with diverticulosis or diverticulitis of the colon until the occurrence of a diagnosis of colorectal cancer, death, or the end of the observation period (December 31, 1985). For additional analysis we also used the inpatient register to search for those patients within our cohort who had undergone resection of the sigmoid colon or a left sided hemicolectomy during follow up through 1983. A total of 507 patients out of the $7159(7 \cdot 1 \%)$ had been operated on. In this category of patients, censoring was done for the occurrence of cancer of the left colon at the date of surgery.

The expected number of cancers was calculated by multiplying the number of person years for each sex by age specific cancer incidence rates for each 5 year age group and calendar year of observation. These expected rates were derived from the study population, that is the Uppsala health care region. For the main analysis, we used a 2 year latency period between first discharge and calculation of observed and expected numbers of cancers. The reason for this approach was to eliminate or to reduce the possible impact of selection bias. Such a bias would occur in patients in whom the symptoms of the cancer were the reason for admission to hospital and who were given the discharge diagnosis of diverticulosis or diverticulitis.

\section{STATISTICAL METHODS}

The standardised incidence ratio (SIR) was defined as the ratio of observed numbers of cancers to those expected. The $95 \%$ confidence interval $(\mathrm{CI})$ of the standardised incidence ratio was then calculated on the assumption that the observed number follows a Poisson distribution. In order to test the existence of a trend the $\chi^{2}$ method was used. ${ }^{21}$

\section{Results}

The cohort with 7159 patients was followed up for 2-20 years, which generated a total of 42615 person years at risk, with a mean duration of 5.95 years of follow up.

When the first 2 years after first discharge were included, a total of 118 patients were diagnosed with colon cancer, compared with the expected number of 49.3 for an SIR of $2.4(95 \%$ CI 2.0, 2.9). During the same period there were 41 cases of rectal cancer, compared with the expected number of 26.5 (SIR $=1 \cdot 6 ; 95 \% \mathrm{CI} 1 \cdot 1$, $2 \cdot 1)$. The increased risk of both colon and rectal cancers was almost entirely caused by an excess number of cases during the early follow up period.

When the first 2 years after discharge were excluded, the relative risk of colon cancer was only slightly increased (SIR $=1.295 \%$ CI 0.9 , 1.6). There was a significantly increased risk of cancer of the left colon (descending and sigmoid colon) $(\mathrm{SIR}=1 \cdot 8 ; 95 \% \mathrm{CI} 1 \cdot 1,2 \cdot 7)$ whereas the observed number of cancers in other parts of the colon was close to the expected number $(\mathrm{SIR}=0.9 ; 95 \%$ CI $0.5,1.4)$. A non-significant increase in relative risk was found for rectal cancer $(\mathrm{SIR}=1 \cdot 195 \% \mathrm{CI} 0 \cdot 7,1 \cdot 7)$ (Table I).

The relative risk for cancer of the colon and rectum was similar in men and women (Table I), and did not seem to be related to age at first discharge (Table II). The possibility that the excess risk of colon cancer, notably left sided, was unevenly distributed by years of follow up was analysed in Table III. A considerably increased relative risk within 2 years of follow up was found for left sided colon cancer and a more

TABLE III Observed number of cases $(O B S)$ and risk of developing colorectal cancer expressed as the standard incidence ratio (SIR), according to the localisation of the cancer and duration of follow up from the first discharge after diverticular disease. $95 \%$ confidence limits in parenthesis

\begin{tabular}{|c|c|c|c|c|c|c|c|c|}
\hline \multirow[b]{3}{*}{ Site } & \multicolumn{8}{|l|}{ Follow up } \\
\hline & \multicolumn{2}{|l|}{$<2 y$} & \multicolumn{2}{|l|}{$2-4 y$} & \multicolumn{2}{|l|}{$5-9 y$} & \multicolumn{2}{|l|}{$>=10 y$} \\
\hline & $O B S$ & $S I R$ & $O B S$ & $S I R$ & $O B S$ & $S I R$ & $O B S$ & $S I R$ \\
\hline $\begin{array}{l}\text { All colon }{ }^{\star} \\
\text { Right }+ \text { transverse colon } \\
\text { Descending + sigmoid colon } \star \\
\text { Rectum }\end{array}$ & $\begin{array}{l}75 \\
20 \\
48 \\
19\end{array}$ & $\begin{array}{c}5 \cdot 8(4 \cdot 6-7 \cdot 3) \\
3 \cdot 0(1 \cdot 9-4 \cdot 7) \\
10 \cdot 7(7 \cdot 9-14 \cdot 2) \\
2 \cdot 7(1 \cdot 6-4 \cdot 2)\end{array}$ & $\begin{array}{r}18 \\
7 \\
8 \\
9\end{array}$ & $\begin{array}{l}1 \cdot 2(0 \cdot 7-1 \cdot 9) \\
0 \cdot 9(0 \cdot 4-1 \cdot 9) \\
1 \cdot 6(0 \cdot 7-3 \cdot 1) \\
1 \cdot 1(0 \cdot 5-2 \cdot 1)\end{array}$ & $\begin{array}{r}19 \\
8 \\
9 \\
8\end{array}$ & $\begin{array}{l}1 \cdot 4(0 \cdot 8-2 \cdot 2) \\
1 \cdot 1(0 \cdot 5-2 \cdot 2) \\
2 \cdot 0(0 \cdot 9-3 \cdot 8) \\
1 \cdot 0(0 \cdot 5-2 \cdot 1)\end{array}$ & $\begin{array}{l}6 \\
1 \\
4 \\
5\end{array}$ & $\begin{array}{l}0.9(0.3-2 \cdot 0) \\
0.3(0.0-1 \cdot 7) \\
1.9(0.5-4.9) \\
1.4(0.5-3.3)\end{array}$ \\
\hline
\end{tabular}

* Including multiple and unspecified sites.

$\star \star$ Trend tests with the $\chi^{2}$ method, ${ }^{20}$ after excluding the first 2 years, $\chi^{2}=13.7$ and $p<0.001$ 
modest increase for cancer of the right colon and of the rectum. After more than 2 years of observation, the excess risk of cancer of the descending and sigmoid colon persisted throughout the observation period and increased significantly ( $p$ for trend $<0.001$ ) the longer the follow up (Table III).

\section{Discussion}

We found a significant, approximately twofold increase in the relative risk of left sided colon cancer in patients with diverticulosis or diverticulitis. Two years or more after the first hospital discharge this increased risk occurred consistently in men and women, at different ages, and it persisted more than 10 years after first discharge. In contrast, we found no evidence of increased risk of right sided colon cancer and only a small, non-significant excess of rectal cancers.

The validity of the diagnosis was assessed in the medical records of 537 consecutive patients given a discharge diagnosis of diverticulosis or diverticulitis at the Uppsala University Hospital 1969-1984 (Stefánsson, unpublished data). In $486(91 \%)$ of the patients the diagnosis had been confirmed by a barium enema, by operation, or both; $x$ ray was negative in $29(5 \%)$, and the diagnostic method was clinical examination alone in $22(4 \%)$ patients. These data indicate that the specificity of a discharge diagnosis of diverticulosis or diverticulitis is high. It is likely, but unproved, that results from one large hospital are representative for the entire health care region. The strength of the association shown in this study would be marginally underestimated if some $10 \%$ of the cohort members did not have diverticular disease or any other disease which entails an increased risk of left sided. colon cancer. Closer surveillance of patients with diverticulosis or diverticulitis in the colon may have lead to increased discovery of cancer of the left colon in our cohort compared with that in the general population. However, if such a bias exists, it should affect the results for rectal cancer most and no excess risk was found for that site. Moreover, closer surveillance might also be protective if premalignant lesions, notably polyps, are detected and removed.

Because the registry started in 1965, a number of patients in the cohort might have had an unnotified discharge before that date. Thus, this series contains a mixture of incident and prevalent cases of patients with diverticular disease. The prevalent cases are likely to have had their disease longer than incident cases. If patients with diverticular disease have an increased risk for developing left sided colon cancer, the prevalent cases should have higher risk of developing left sided colon cancer than the incident cases. But as the group of prevalent cases is small and the increase in cancer risk is not more than about twice the normal risk, this group will not influence noticeably the results in Table III.

The absence of an increase in the relative risk of cancer in the right colon and rectum 2 years or more after the first discharge contradicts the hypothesis that diverticulosis of the colon and colorectal cancer in general have aetiological factors in common, as proposed in the early 1970 s. $^{13-5}$ This absence of an association also agrees with two previous studies. In one casecontrol study, 119 patients with colon cancer were compared with hospital controls who had had a barium enema because of gastrointestinal symptoms but in whom no carcinoma was diagnosed. There was no difference in the prevalence of diverticulosis of the colon between cases and controls. ${ }^{16}$ In another case-control study, 150 patients with diverticulosis of the colon and abdominal symptoms were compared with controls who had abdominal symptoms but no diverticulosis. Both groups underwent colonoscopy and the risk of cancer was found to be the same in both groups. ${ }^{17}$

The significant trend of an increased risk of cancer of the left colon the longer the follow up suggests that the association between diverticular disease and cancer of the left colon may be causal. Different, possible biological explanations of such an association exist. The most common site for diverticular disease is in the sigmoid colon. ${ }^{22}$ Likewise the concentration of bacteria is high in the left colon and some types are known to produce carcinogens or cocarcinogens through degradation of biliary steroids in the faeces. ${ }^{23-25}$ Carcinogens may be trapped in the diverticulas and thereby establish prolonged contact with the colonic mucosa. According to another suggestion, the DNA in the mucosal cell nuclei becomes more susceptible to damage and malignant transformation when the turnover of cells increases because of chronic inflammation. ${ }^{26}$ This could be the case in patients with diverticulitis of the sigmoid colon as in patients with ulcerative colitis, ${ }^{27}$ Crohn's disease, ${ }^{28}$ and those patients with gastric helicobacter pylori infection of the stomach. ${ }^{29}$

We conclude that the increasing relative risk for cancer of the left colon in patients with diverticular disease may reflect a causal relationship. In clinical practice this means that malignant disease should be excluded if a patient who has had diverticular disease has a relapse of symptoms. This excess risk is, however, not great enough to justify any screening procedures for early detection of cancer in patients with known diverticulosis of a history of diverticulitis of the colon.

We wish to thank Professor Hans Olov Adami, The Cance Epidemiology Unit, University Hospital, Uppsala, Sweden, for his help and advice with the manuscript

1 Burkitt DP. Epidemiology of cancer of the colon and rectum. Cancer 1971; 28: 3-13.

2 Painter NS. The cause of diverticular disease of the colon, its symptoms and its complications. Fournal of the Royal College of Surgeons Edinburgh 1985; 30: 118-22.

3 Painter NS, Burkitt DP. Diverticular disease of the colon: a deficiency disease of western civilization. $B M \mathcal{F} 1971$; ii: $450-4$.

4 Burkitt DP. Colonic-rectal cancer: fiber and other dietary factors. Am F Clin Nutr 1978; 31: S58-64.

5 Burkitt DP, Walker ARP, Painter NS. Dietary fiber and disease. FAMA 1974; 229: 1068-74.

6 Wynder EL, Shigematsu T. Environmental factors of cancer of the colon and rectum. Cancer 1967; 20: 1520-61.

7 Levy N, Stermer E, Simon J. The changing epidemiology of diverticular disease in Israel. Dis Colon Rectum 1985;28: diverticul

8 Stemmermann GN, Yatani R. Diverticulosis and polyps of the large intestine. Cancer 1973; 31: 1260-70.

9 Haenszel W, Kurihara M. Studies of Japanese migrants. I. Mortality from cancer and other diseases among Japanese in the United States. F Nat Cancer Inst 1968; 40: 43-68. 
10 Staszewski J, Haenszel W. Cancer mortality among the Polishborn in the United States. F Nat Cancer Inst 1965; 35: 291-7.

11 Modan B, Barell V, Lubin F, Modan M, Greenberg RA, Graham S. Low-fiber intake as an etiological factor in cancer of the colon. F Natl Cancer Inst 1975; 55:15-8.

12 Brodribb AJM. Dietary fiber in diverticular disease of the colon. In: Spiller GA, Kay RM. eds. Medical aspects of colon. In: Spiller GA, Kay RM. eds. Medical aspect

13 Gear JSS, Fursdon P, Nolan DJ, Ware A, Mann JI, Brodribb AJM. Symptomless diverticular disease and intake of dietary

14 Painter NS, Almeida AZ, Colebourne KW. Unprocessed bran in treatment of diverticular disease of the colon. $B M \mathcal{F} 1972$; ii: $137-40$.

15 Manousos O, Day NE, Tzonou A, Papadimitriou C Kapetanakis A, Polychronopolou-Trichopoulou A, Trichopoulos D. Diet and other factors in the aetiology of
diverticulosis: an epidemiological study in Greece. Gut 1985; 26: 544-9.

16 McCallum A, Eastwood A, Smith AN, Fulton PM. Colonic diverticulosis in patients with colorectal cancer and in controls. Scand F Gastroenterol 1988; 23: 284

17 Morini S, De Angelis P, Manurita L, Colavolpe V. Association of colonic diverticula with adenomas and carcinomas. A colonoscopic experience. Dis Colon Rectum 1988; 31: 7936.

18 Naessén T, Parker R, Persson I, Zack M, Adami HO. Time rends in incidence rates of first hip fracture in the Uppsal health care region, Sweden, 1965-1983. Am 7 Epidemiol 1989; 130: 289-99.

19 Mattsson B. The completeness of registration in the Swedish
Cancer Registry. Statistical reports HS 1977. No 15 Stockholm: Swedish Board of Health and Welfare, 1977.

20 The Cancer Registry. Cancer incidence in Sweden 1958-1987. Stockholm: Swedish Board of Health and Welfare, 19601990.

21 Breslow NE, Day NE, eds. Statistical methods in cancer research. Vol II The design and analysis of cohort studies. Lyon:
International Agency for Research on Cancer, IARC International Agency for Research

22 Zollinger RW. The prognosis in diverticulitis of the colon. Arch Surg 1968; 97: 418

23 Hill MJ, Drasar BS, Williams REO, Meade TW, Cox AG, Simpson JEP, Morson BC. Faecal bile-acids and clostridia in patients with cancer of the large bowel. Lancet 1975; i: 535-

24 Hill MJ. Colon cancer: A disease of fibre depletion or of dietary excess? Digestion 1974; 11 : 289-306.

25 Wynder EL, Reddy BS. The epidemiology of cancer of the large bowel. Am f Dig Dis 1974; 19: 937-46.

26 Ames BN, Gold LS. Too many rodent carcinogens: mitogenesis increases mutagenesis. Science 1990; 249: 970-1.

27 Ekbom A, Helmick C, Zack M, Adami HO Ulcerative colitis and colorectal cancer. A population-based study. $N$ Engl $\mathcal{F}$ and colorectal cancer. A

28 Ekbom A, Helmick C, Zack M, Adami HO. Increased risk of large bowel cancer in Crohn's disease with colonic involvement. Lancet 1990; 336: 357-9.

29 Parsonnet J, Friedman GD, Vandersteen DP, Chang Y, Vogelman J, Orentriech N, Sibley RK. Helicobacter pylori infection and the risk of gastric carcinoma. $N \mathrm{Engl} \mathcal{F} \mathrm{Med}$ 1991; 325: 1127-31 